\title{
Strategic Buying or Selling?: The Behavior of Vertically-Integrated Firms in the Intermediate Goods Market
}

\author{
Kuang-Cheng Wang \\ Chang Gung University \\ Hui-Wen Koo and Tain-Jy Chen \\ National Taiwan University
}

\begin{abstract}
This paper considers a successive oligopoly model in which a verticallyintergrated firm(VI firm) can buy or sell intermediate goods. We find that when there are only a small number of VI firms in the market, they tend to $b$ uyor even to store up intermediate goods. In our setting, a vertical merger wil $l$ not result in market foreclosure and it always in creases social welfare.
\end{abstract}

- JEL Classifications: L11, L13

- Key words: Market structure,Vertically-Integrated firms, Strategic buying

\section{Introduction}

Mergers always attract regulators' attention, because of their possible negative effect on social welfare. However, economists show that a vertical merger might increase social welfare instead. For instance, Spengler (1950) shows that if both the downstream and upstream markets are monopolized, then their merger can avoid the problem of "double marginalization," and will lead to a decline in the final goods price and improve social welfare. In the case of an oligopoly, Salinger

\footnotetext{
*Corresponding address: Kuang-Cheng Wang, Assistant Professor, Center for General Education, Chang Gung University, 259 Wan-Hwa 1st Rd., Kwei-Shan Tao-Yuan, Taiwan 333, R.O.C. Tel: +886-3-211-8800, ext 3298, Fax: +886-3-211-8700, E-mail: andykcwang@giga.net.tw, "Hui-Wen Koo and Tain-Jy Chen, Professor, Department of Economics, National Taiwan University

(C2005-Center for International Economics, Sejong Institution, All Rights Reserved.
} 
(1988) finds that a vertical merger may result in market foreclosure and lower social welfare. This paper relaxes the assumption by Salinger (1988) that vertically-integrated (VI) firms do not trade in the intermediate goods market and reexamine the issue. We find that a vertical merger never results in market foreclosure and social welfare always improves as a result.

Greenhut and Ohta (1979) are the first to analyze vertically-related markets. They set up a successive model and compared the equilibrium prices when all firms are non-integrated and when some are integrated. Using the setup by Greenhut and Ohta (1979), Salinger (1988) analyses the possibility of market foreclosure after a vertical merger occurs. Both papers assume that VI firms do not intervene in the intermediate goods market, i.e., VI firms neither buy from nonintegrated intermediate goods supplier, nor do they sell the intermediate goods to non-integrated downstream firms. ${ }^{1}$

Schrader and Martin (1998) try to relax Salinger's assumption and consider VI firms that trade in the intermediate goods market. They assume that VI firms always buy intermediate goods in the market, and in their model each VI firm holds a "Cournot belief": when one more unit of intermediate goods is sold, final goods supplied in the downstream market are expected to increase by one. $^{2}$ This Cournot belief cannot be justied rationally, when one considers all possible reactions to a VI firm's sale of intermediate goods. This paper instead considers VI firms as Cournot players and analyzes the strategic behavior of a VI firm in the market of intermediate goods.

Following Spencer and Jones (1992), we consider VI firms to intervene in the intermediate goods market so as to raise their rivals' production cost. Under this assumption, we show that VI firms may strategically buy or sell intermediate goods. The behavior of VI firms is closely related to the overbuying behavior described by Salop and Scheman (1983) and (1987), where a predator purchases an unnecessarily large amount of inputs in order to raise the input price. The difference

\footnotetext{
${ }^{1}$ VI firms do intervene intheinter mediate market. In Taiwan, Nan Ya Corporation and Formosa Chemical \& Fiber Corporation, which both belong to Formosa Enterprise Group, the top 1 enterprise group in Taiwan, are perfect examples. Nan Ya Corporation sells intermediate goods, polyester chips and polyester fully oriented yarn (besides its final product, polyester draw textured yarn), as does Formosa Chemical \& Fiber Corporation which sells not only nylon draw textured yarn to the market, but also the intermediate material, nylon chip and nylon fully oriented yarn. This suggests to us that it seems unsuitable to assume that VI firms withdraw from the intermediate goods market.
}

${ }^{2}$ Schrader and Martin(1998), p.325. 
is that their predator cannot self-supply inputs, while ours can.

The rest of the paper is organized as follows. Section 2 sets up the model. In section 3 we characterize the Cournot-Nash equilibrium. Section 4 discusses the problem of market foreclosure and social welfare, and section 5 concludes.

\section{The Model}

We consider the market of good $y$ and the market of its intermediate good $x$ to be both oligopolistic with $M$ and $N$ producers respectively engaged in Cournot competition. Among them, there are $L$ VI firms that self-supply the intermediate goods and think strategically whether to sell or to buy on the intermediate goods market in order to change the cost of final goods produced by the $M-L$ non integrated downstream firms.

To simplify the analysis, we assume that one unit of the intermediate goods can be transformed into a unit of the final goods at a constant marginal $\operatorname{cost} \mathbf{c}_{F}$. The marginal cost of producing the intermediate good, $\mathrm{c}_{I}$, is also assumed to be constant. A non-integrated downstream firm is assumed to be a price taker when buying the intermediate good $x$, and the unit cost for it to produce $y$ is thus $P_{x}+c_{f}$, where $P_{x}$ denotes the market price of $x$.

With different cost structures, the VI firms and the independent downstream firms compete to sell $y$. The market demand for the final goods is assumed to be linear:

$$
P_{y}=a-b Y,
$$

where $P_{y}$ and $Y$ denote the price and quantity of the final good. We shall assume the demand to be high enough, i.e., $a>c_{I}+c_{F}$, so as to exclude the possibility of corner solutions.

We model the relationships between the upstream and the downstream industries as a two-stage game. In the first stage, facing the derived demand of intermediate goods, upstream firms determine their sales of $x$ in a Cournot competition. In the second stage, downstream firms determine sales of final goods. We shall solve the subgame perfect equilibrium of this industry.

\section{A. Downstream Competition}

We first study the subgame in the final goods market with the price of 
intermediate goods $P_{x}$ given. We shall index the VI firms from 1 to $L$, and the nonintegrated downstream firms from $L+1$ to $M$. For the non-integrated firms, their profit maxization problem is simply:

$$
\underset{y_{i}}{\max } \pi_{i}=\left(P_{y}-c_{F}-P_{x}\right) y_{i}, \quad i=L+1, \ldots, M
$$

where $y_{i}$ denotes firm $i$ 's output.

The profit function of a VI firm (denoted $\mathrm{j}$ ) is more complicated. The profit of firm $j$ depends, on one hand, on the sale of final goods $y_{j}$; and on the other hand, it depends on how many intermediate goods are self-supplied. Though we have $P_{x}>c_{I}$ in equilibrium for a non-integrated upstream firm to survive (i.e., outsourcing is never a cheaper means for the VI firm), then the VI firm may still strategically consider to purchase $x$ in order to raise $P_{x}$, and hence the cost of independent downstream firm. Let $x_{j}$ denotes the sale of $x$ by firm $\mathrm{j}$ on the intermediate goods market. Here, $x_{j}<0$ indicates that firm $j$ has purchased $x_{j}$ units of intermediate goods. When $x_{j} \geq 0$ or when $x_{j}<0$ and $y_{j}+x_{j} \geq 0$, then firm $j$ 's problem is:

$$
\max _{y_{j}} \pi_{j}=\left(P_{y}-c_{I}-c_{F}\right) y_{i}+\left(P_{x}-c_{I}\right) x_{j}, \quad j=1, \ldots, L
$$

When $x_{j}<0$ and $y_{j}+x_{j}<0$, firm $j$ buys more intermediate goods than its production needs, and will keep the inventory of $-\left(x_{j}+y_{j}\right)$ units of intermediate goods. Assuming that the inventory has the same value as its production $\operatorname{cost} \mathrm{c}_{I}$, (3) still properly depicts firm $j$ 's maximization problem.

In sum, given $P_{x}$, one can solve the sales of final goods by two types of firms, $y_{i}$ $\left(P_{x}\right)$ and $y_{j}\left(P_{x}\right)$, in a Cournot competition. In the following, we shall explain how $P_{x}$ is determined in the first stage of the game.

\section{B. The Market of Intermediate Goods}

We assume the non-integrated downstream firms to be price takers in the market of intermediate goods. Because one unit of final goods takes a unit of intermediate goods to produce, the derived demand for $x$ is:

$$
X\left(P_{x}\right)=\sum_{i=L+1}^{M} y_{i}\left(P_{x}\right),
$$

where $y_{i}\left(P_{x}\right)$ is solved as the previous section describes. 
On the other hand, the producers of $x$ are assumed to have a Cournot competition in the market of intermediate goods. For a non-integrated upstream firm, indexed from $L+1$ to $N$, its problem can be written as:

$$
\max _{x_{k}} \pi_{k}=P_{x} x_{k}-c_{I} x_{k}, \quad k=L+1, \ldots, N,
$$

where $x_{k}$ denotes firm $k$ 's output. For a VI firm, its problem is:

$$
\max _{x_{j}} \pi_{j}=\left(P_{x}-c_{I}\right) x_{j}+\pi_{j}^{D}\left(P_{x}\right), \quad j=1, \ldots, L,
$$

where $\pi_{j}^{D}$ is the downstream profit, $\pi_{j}^{D}=\left(P_{y}-c_{I}-c_{F}\right) y_{j}\left(P_{x}\right)$. When $x_{j}<0$ in (5), a VI firm is a buyer of the intermediate goods, and we assume it to remain influential in determining $P_{x}$. Later in section 5, we shall turn to consider VI firms that become price takers when purchasing $x$.

\section{The Behavior of VI Firms: Strategic Buying or Strategic Selling}

This section solves the two-stage game and studies strategies of a VI firm in the market of intermediate goods.

\section{A. The Equilibrium in the Downstream Market}

The sales of final goods are determined by the market demand in (1) and the F.O.C.s of profit maximization problems listed in (2) and (3). In a Cournot equilibrium, the optimal sales by a VI firm, $y_{j}^{*}$, and by a non-integrated downstream firm, $y_{j}^{*}$, are:

$$
\begin{aligned}
y_{j}^{*} & =\frac{a-c_{F}+(M-L) P_{x}-(M-L+1) c_{I}}{b(M+1)} ; \\
y_{i}^{*} & =\frac{a-c_{F}+L c_{I}-(L+1) P_{x}}{b(M+1)} .
\end{aligned}
$$

Summing up (6) and (7) across all firms, the total sales of final goods and their market price are:

$$
\begin{aligned}
Y^{*} & =\frac{M\left(a-c_{F}\right)-L c_{I}-(M-L) P_{x}}{b(M+1)} \\
P_{y}^{*} & =\frac{a+M c_{F}+L c_{I}+(M-L) P_{x}}{M+1}
\end{aligned}
$$


With (6) and (8), the downstream profit of each VI firms can be given:

$$
\pi_{j}^{D}=\frac{\left(a-c_{F}-(M-L+1) c_{I}-(M-L) P_{x}\right)^{2}}{b(M+1)^{2}} .
$$

\section{B. Strategic Behavior in the Upstream Market}

Summing up (7) across all non-integrated downstream firms, we obtain the derived demand for the intermediate goods:

$$
P_{x}=\frac{a+L c_{I}-c_{F}}{L+1}-\frac{b(M+1)}{(L+1)(M-L)} X^{D}
$$

where $X^{D}$ stands for the quantity demanded. The suppliers here of intermediate goods are Cournot competitors and the F.O.C.s of their supplying behavior are derived from (4) and (5) with (9) to specify $\pi_{j}^{D}\left(P_{x}\right)$ in $(5),{ }^{3}$ and along with the derived demand in (10), we can get the equilibrium intermediate outputs of nonintegrated firms and VI firms to be: ${ }^{4}$

$$
\begin{aligned}
& x_{k}^{*}=\frac{(M-L)(L+1)(M+2 L+1)\left(a-c_{I}-c_{F}\right)}{b(1+M)\left(1+L+2 L^{2}+M-L M+(1+L)(1+M) N\right)}, \\
& x_{j}^{*}=\frac{(M-L)(L(3+2 L+M-2 N)-1-M-2 N)\left(a-c_{I}-c_{F}\right)}{b(1+M)\left(1+L+2 L^{2}+M-L M+(1+L)(1+M) N\right)} .
\end{aligned}
$$

(10), (13) and (14) imply that the price of an intermediate good is:

$$
P_{x}^{*}=\frac{\left[2 L^{2}+L(1+M)(N-1)+N+M N\right] c_{I}+(1+2 L+M)\left(a-c_{F}\right)}{1+L+2 L^{2}+M-L M+(1+L)(1+M) N}
$$

Substituting (13) into (6), the equilibrium final output of each VI firm is:

$$
y_{j}^{*}=\frac{(1+M+N+M N)\left(a-c_{I}-c_{F}\right)}{b\left(1+L+2 L^{2}+M-L M+(1+L)(1+M) N\right)} .
$$

\footnotetext{
${ }^{3}$ When studying a VI firm's behavior, Scharder and Martin(1998) assume that when a VI firm sells one more unit of intermediate good, there will automatically be one more unit of final good to be produced, i.e., $\partial\left(\sum_{j=1}^{L} y_{j}+\sum_{i=L+1}^{M} y_{i}\right) / \partial x_{j}=1$. In our model, (8) and (10) imply $\partial\left(\sum_{j=1}^{L} y_{j}+\sum_{i=L+1}^{M} y_{i}\right) / \partial x_{j}=1 /(L+1)<1$.

${ }^{4}$ When $\left(a-c_{\Gamma} c_{F}\right)>0$, the second-order condition is satised in our model.
} 
Note that a non-integrated firm always produces a positive quantity, i.e., $x_{j}^{*}>0$, while a VI firm can either buy or sell in the intermediate goods market, i.e., $x_{j}^{*} \geq 0$.

When the upstream profit from selling intermediate goods exceeds (falls short of) the loss that this sale brings to the downstream profit, then the VI firm sells (buys) intermediate goods.

Given the total number of producers of two goods, $M$ and $N$, (14) indicates that the critical number of VI firms that determines strategic selling and buying behavior is $:^{5}$

$$
L^{*}=1 / 4\left(-3-M+2 N+\sqrt{17+14 M+M^{2}+4 N-4 M N+4 N^{2}}\right)>1 .
$$

When $L>(<) L^{*}$, a VI firm sells (buys) intermediate goods, i.e. $x_{j}^{*}>(<) 0$, and when $L=L^{*}$, a VI firm does not trade in the intermediate goods market.

When a VI firm buys intermediate goods strategically, it can even purchase more than its future needs for producing $y$. In this case, a VI firm stores up inventory of $x$. Let $z_{j} \equiv x_{j}+y_{j}$. When $z_{j}<0$, it must be that $x_{j}<0$ and $\left|x_{j}\right|>y_{j}$, and $\left|z_{j}\right|$ stands for the inventory of intermediate goods that VI firm $j$ holds. On the other hand, $\mathrm{z}_{j}>0$ specifies the quantity of intermediate goods produced by VI firm $j$. Adding (12) and (14),

$$
\begin{aligned}
& z_{j}^{*}=\frac{\left(a-c_{F}-c_{I}\right)}{b(1+M)\left(1+L+2 L^{2}+M-L M+(1+L)(1+M) N\right)} \\
& \left.\left\{1-2 L^{3}+M+N-M N+L^{2}(-3+M+2 N)+L(1+M)(4+M-N)+3 N\right)\right\} .
\end{aligned}
$$

Given $M$ and $N$, let $L^{* *}$ denote the critical number of VI firms that determine when VI firms will store up the inventory of intermediate goods, that is, $L^{* *}=$ $\left\{L \mid z_{j}^{*}=0\right.$ and $\left.0 \leq L \leq L^{*}\right\}$.

Lemma 1: (a) If $L^{* *}$ exists, then it is unique. (b) When $L \leq L^{*}, z_{j}^{*}>(<) 0$

$$
\text { if } L>(<) L^{* *} \text {. (c) } L^{* *} \geq 1 \text { if }-3+M^{2}+2 M(3-N)+6 N \leq 0 \text {. }
$$

The proof of Lemmal. See the appendix.

Excluding the possibility of a fractional number of VI firms, $L<1$. To summarize the analysis about $L^{*}$ and $L^{* *}$, we conclude:

${ }^{5}$ Here $L^{*}$ has another negative root, which is irrelevant to our discussion. 
Proposition 1: Given $M$ and $N$, when the industrial structure satisfies the condition $-3+M^{2}+2 M(3-N)+6 N \leq 0\left(L^{*}>L^{* *} \geq 1\right)$, thenVI firms' behavior is as follows.

(1). If $L>L^{*}$, then VI firms produce more intermediate goods than they need, and sell the extra to the independent downstream firms.

(2). If $L=L^{*}$, then VI firms do not trade in the market of intermediate goods.

(3). If $L^{* *}<L<L^{*}$, then VI firms produce only part of the intermediate goods they need and buy the remainder from independent upstream firms.

(4). If $L=L^{* *}$, then VI firms buy exactly the amount of intermediate goods they need to produce the final goods.

(5). If $L^{* *}>L \geq 1$, then VI firms buy the intermediate goods more than is needed and store up the surplus as an inventory.

When the industrial structure satises the condition: $-3+M^{2}+2 M(3-N)+6 N>0$, then only (1), (2) and (3) apply.

Proposition 1 states that when the number of upstream and downstream firms $(N, M)$ are fixed, the possibility of strategic buying turns slimmer with a larger number of VI firms. The economic intuition is as follows. There are three kinds of players in the upstream industry: $N-L$ pure suppliers, $M-L$ pure demanders, and $L$ VI firms whose strategic thinking determine whether they will buy or sell.

(1) The number of pure suppliers decreases with $L$. When there are less of these single-minded sellers, selling intermediate goods becomes more profitable for VI firms. (2) Buying to raise the price of intermediate goods works more effectively when the number of pure suppliers is small, and so the incentive of strategic buying increases with $L$. (3) When $L$ increases, the number of pure demanders decreases with $L$, and the incentive for VI firms to sell and profit in the upstream market diminishes. (4) With a smaller number of independent downstream firms, raising their cost of intermediate goods $\left(P_{x}^{*}\right)$ will have a smaller impact on VI firms' downstream profit. Thus, the incentive for strategic buying falls off with L.(5) Strategic buying is costly to a VI firm, while its benefit, accrued from the weakened independent downstream firms, is shared with all peers of the VI firms. When $L$ increases, this external (free-rider) effect is more serious, and we expect VI firms to be engaged in less strategical buying. From above, (1), (4), (5) and (2) and (3) of the eects are opposites. Proposition 1 states that as $L$ increases, effect (1), (4), and (5) will overtake (2) and (3), and VI firms will turn into sellers of intermediate goods.

When the number of the independent downstream suppliers $(M-L)$ increases while $L$ is fixed, there are two effects on VI firms' behavior. On the one hand, 
selling intermediate goods becomes more profitable when the number of pure demanders of intermediate goods increases. On the other hand, the incentive for raising the cost of non-integrated downstream firms also increases.

When the number of independent upstream firms $(N$-L) increases, there are also two effects on VI firms. As the upstream market becomes more competitive, the profit from selling intermediate goods is smaller. While this discourages VI firms to sell intermediate goods, curbing the sales in order to raise the cost of nonintegrated downstream firms becomes more difficult when there are more independent suppliers of intermediate goods. Intuitively, it is difficult to judge which effect is stronger, but the following proposition shows that in our model, when $M$ or $N$ increases, the net effect on VI firms' behavior is always unambiguous.

Proposition 2: Given the number of VI firms $(L)$, when there are more independent downstream (upstream) firms, the VI firms are more inclined to sell (buy) intermediate goods.

\section{Proof:}

From proposition $1, L^{*}$ is the critical point for strategic buying. To differentiate $L^{*}$ with $M$ and $N$ respectively, we have:

$$
\begin{aligned}
& \frac{\partial L^{*}}{\partial M}=\frac{1}{4}\left(-1+\frac{7+M-2 N}{\sqrt{17+14 M+4 N+(M-2 N)^{2}}}\right)<0 ; \\
& \frac{\partial L^{*}}{\partial N}=\frac{1}{4}\left(2+\frac{2 N+2(N+1)-2 M}{\sqrt{17+14 M+4 N+(M-2 N)^{2}}}\right)>0 .
\end{aligned}
$$

\section{Zero Inventory Value}

In the previous section, we consider the unit inventory value of intermediate goods to be its production cost, $\mathrm{C}_{I}$. In this section, we will examine another extreme case: the inventory value is null, i.e., VI firms have no future chance to use or sell final goods when our two-stage game is over. In this case, when the VI firm stores up inventory of intermediate goods, its maximization problem changes to:

$$
\begin{aligned}
& \underset{y_{j}}{\max } \pi_{j}=P_{y} y_{j}-c_{F} y_{j}+P_{x} x_{j}, \\
& \text { s.t. } y_{j} \geq 0 \quad y_{j}+x_{j} \leq 0 .
\end{aligned}
$$

When the VI firm does not store up inventory, its problem stays the same as in 
(3). In other words, the $\mathrm{L}$ domain that (3') concerns here is in the range $L \leq L^{* *}$. Thus, in the following we shall explore the case when the constraint $y_{j}+x_{j} \leq 0$ is not binding in (3').

We shall solve the problem backward. With the F.O.C.s of (2) and (3), the sales of final goods by a VI firm and an independent downstream firm are, respectively:

$$
\begin{aligned}
y_{j}^{*} & =\frac{a-c_{F}+(M-L) P_{x}}{b(M+1)} \\
y_{i}^{*} & =\frac{a-c_{F}+(L+1) P_{x}}{b(M+1)}
\end{aligned}
$$

From (1), (18), and (19), the downstream profit of the VI firm is:

$$
\pi_{j}^{D}=\frac{\left(a-c_{F}+(M-L) P_{x}\right)^{2}}{b(M+1)^{2}}
$$

Equation (19) implies that the derived demand of the intermediate goods is:

$$
P_{x}=\frac{a-c_{F}}{L+1}-\frac{b(M+1)}{(M-L)(L+1)} X^{D}
$$

In the first stage, the profit maxization problems of two types of upstream suppliers are specified in (3') and (4), where the derived demand is given by (21) and $\pi_{j}^{D}\left(P_{x}\right)$ by (20). From the F.O.C.s, the trade volume of a non-integrated firm and a VI firm are, respectively: ${ }^{6}$

$$
\begin{array}{cc}
x_{k}^{*} & \frac{(1+L)(M-L)\left\{\left(a-c_{F}\right)(1+2 L+M)-\left[1+M+L(2+L(3+M)] c_{I}\right\}\right.}{b(1+M)\left(1+L+2 L^{2}+M-L M+(1+L)(1+M) N\right)} \\
x_{j}^{*} & \frac{(M-L)}{b(1+M)\left(1+L+2 L^{2}+M-L M+(1+L)(1+M) N\right)} \\
& \left\{(1+L)[1-M+L(3+M)](N-L) c_{I}+\left(a-c_{F}\right)[-1-M+L(3+2 L+M-2 N)-2 N\} .\right.
\end{array}
$$

We cannot tell the sign of $x_{k}^{*}$ by (22) only, but it can be easily checked that $x_{k}^{*}>$ 0 if $x_{j}^{*} \leq 0$. Therefore, we do not have to worry about the possibility of a corner solution for non-integrated upstream firms when VI firms store up inventory.

Substituting (22) and (23) into (21), we can obtain $P_{x}^{*}$, and with $P_{x}^{*}$ in (18), we have:

\footnotetext{
${ }^{6}$ The second-order conditions are also satised.
} 


$$
y_{j}^{*}=\frac{(1+L)(M-L)(N-L) c_{I}+(1+M+N+L N)\left(a-c_{F}\right)}{b\left(1+L+2 L^{2}+M-L M+(1+L)(1+M) N\right)} \geq 0
$$

From (23) and (24), the quantity of the intermediate goods that the VI firm produces is:

$$
\begin{aligned}
& z_{j}^{*}=y_{j}^{*}+x_{j}^{*} \\
& =\frac{\left[1-2 L^{3}+M+N-M N+L^{2}(-3+M+2 N)+L(1+M(4+M-N)+3 N)\right]\left(a-c_{F}\right)}{b(1+M)\left(1+L+2 L^{2}+M-L M+(1+L)(1+M) N\right)}+ \\
& \frac{(1+L)(M-L)(2+L(3+M))(N-L) c_{I}}{b(1+M)\left(1+L+2 L^{2}+M-L M+(1+L)(1+M) N\right)}
\end{aligned}
$$

The above analysis ignores the possibility of a corner solution in (3'), which we shall now turn to. Define $L^{* * *}=\left\{L \mid z_{j}^{*}=0\right.$ and $\left.L \in\left[0, L^{* *}\right]\right\}$.

Lemma 2: If $L^{* * *}$ exists, then it must be unique.

The proof of Lemma 2. See the appendix.

Proposition 3: If $L^{* * *}$ exists:

(1). When $1 \leq L<L^{* * *}$, VI firm(s) will buy strategically more intermediate goods than their production needs;

(2). when $L^{* * *} \leq L \leq L^{* *}$. VI firm(s) will purchase exactly enough intermediate goods for its production of final goods.

The proof of Proposition 3. See the appendix.

Comparing propositions 1 and 3 , we nd that when the unit inventory value of intermediate goods is zero instead of $C_{I}$, VI firms are less likely to store up

Figure 1. The Behavior of VI Fifirms

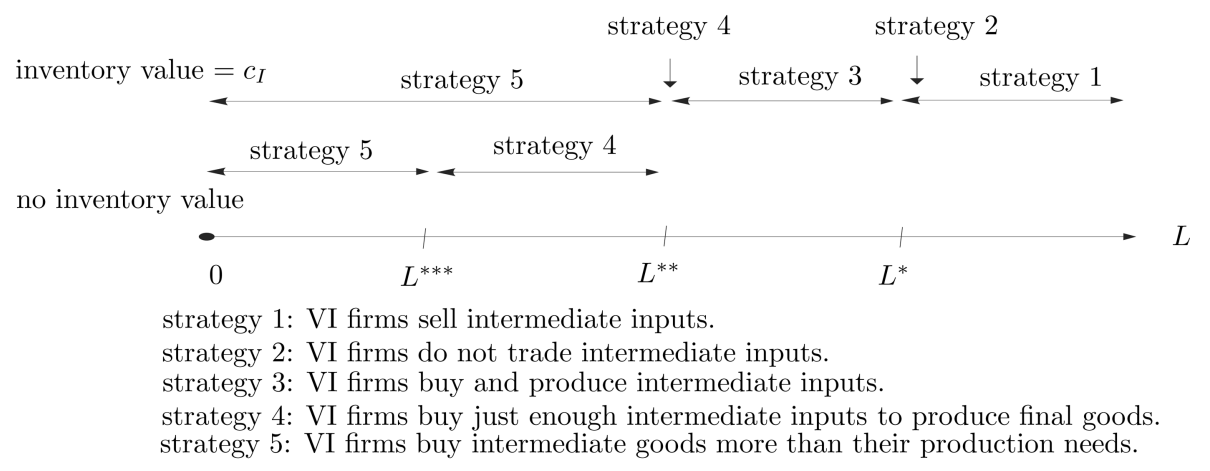


inventory because it is more expensive to raise rivals' cost by storing up inventory $\left(L^{* * *}<L^{* *}\right)$. Figure 1 summarizes the results of propositions 1 and 3. In figure $1, \mathrm{VI}$ firms are inclined to purchase intermediate goods when $L$ is small. Because $L^{*}>1$, we have:

Corollary 1: When there is only one VI firm in the industry, it always purchases the intermediate goods no matter if the inventory value is $\mathrm{c}_{I}$ or 0 .

When a VI firm purchases intermediate goods strategically, there is an external benefit to other VI firms. When there is only one VI firm in the industry, all benefit from raising the rivals' cost accrues to the firm itself, and in our simple setting, the firm will buy intermediate goods. The comparison between $L^{* *}$ and 1 is ambiguous. When $L=1$, the VI firm may or may not buy more intermediate goods than it needs for production.

Corollary 1 illustrates well the case of Aluminum Company of America (Alcoa) v. U.S. (1941). Between 1912 and 1940, Alcoa maintained a large share of the aluminum market (between $80 \%$ and $90 \%$ ). Before World War II, aluminum was produced by combining electricity and bauxite in fairly stable proportions: four tons of bauxite with 22,400 kilowatt hours of electricity yields one ton of aluminum. ${ }^{7}$ Because electricity is an important intermediate good to produce aluminum, Alcoa aggressively invested in electricity, especially in hydroelectric power, exceeding what it needed to produce aluminum ingot. Near the end of 1930, Alcoa was accused of purchasing more hydroelectric power than it used and withholding the excess capacity from its rivals. The trial lasted for many years, and in 1941 Alcoa was judged to be guilty under the antitrust law. ${ }^{8}$

\section{Vertical Merger}

This section discusses whether a vertical merger will cause market foreclosure as considered in Salinger (1988). We shall also study the consequence of a vertical merger on social welfare. To simplify the analysis, we consider the value of one unit of inventory to be $\mathrm{c}_{I}$.

\footnotetext{
${ }^{7}$ Lopataka and Godek(1992), p.312.

${ }^{8}$ Krattenmaker and Salop(1987, p.227) allege that Alcoa only purchased exclusive covenants for not selling electricity to other aluminum producers. The Justice Department of the U.S. thought that Alcoa purchased substantial quantities of mechanical power. However, Lopatkaand Godek(1992, p. 320 ) hold the opposite opinion.
} 


\section{A. Market Foreclosure}

Following Salinger (1988), we consider that a vertical merger will cause market foreclosure if the price of the intermediate goods goes up after the merger, i.e., $\partial P_{x} / \partial L>0$ differentiating equation (13) with respect to $L$, we have:

Proposition 4: Market foreclosure never takes place, when the value of unit inventory is $C_{I}$.

Proof:

Differentiating $P_{x}^{*}$ in (13) with respect to $L$,we have:

$$
\frac{\partial P_{x}^{*}}{\partial L}=\frac{\left[4 L^{2}+4 L(M+1)-(M+1)^{2}+\left(M^{2}-1\right) N\right]\left(a-c_{I}-c_{F}\right)}{\left(1+L+2 L^{2}+M-L M+(1+L)(1+M) N\right)^{2}}
$$

When $N>L \geq 1$ and $M>L \geq 1, \partial P_{x}^{*} / \partial L$ is always negative.

Proposition 4 is quite different from Salinger (1988). In Salinger's model, market foreclosure will (not) take place when $L>(<) N / 2$. This is because he did not consider possible intervention of VI firms in the market of intermediate goods, and simply assumes that vertical merger simply reduces the numbers of sellers and buyers of intermediate goods by one each. When $L>(<) N / 2$, the decrease in demand is smaller (larger) than that of supply, and market foreclosure will (not) take place. In our model, when $L$ increases, there are two additional eects. First, the new VI firm will change its role to purchase (or to sell less than before) when $L<$ (>) $L^{*}$. Second, a new vertical merger will influence the behavior of other incumbent VI firms. If this merger pushes $L$ to cross the threshold $L^{*}$, then the incumbent VI firms will change from a strategic buyer to a strategic seller due to this merger. On the other hand, after $L$ increases, if $L$ remains in the region $L<$ $(>) L^{*}$, then the incumbent VI firms will strategically buy less (sell more) intermediate goods from (to) the market. In sum, we observe that the price of intermediate goods declines after a vertical merger.

\section{B. Social Welfare}

Social welfare is solely decided by the final goods price, $P_{y}$, in our successive oligopoly model. There is no need to evaluate production efficiency, because either intermediate goods or final goods are produced at the same unit cost among all firms. In equilibrium, the unit consumption value always exceeds the unit production cost. The lower $P_{y}$ is, the more trading benefit will be realized. Substituting 
(13) into (8), we have the reduced form of the final goods price:

$$
P_{y}^{*}=\frac{a(1+M+N+L N)+[L(1+2 L-M)+(1+L) M N]\left(c_{I}+c_{F}\right)}{1+L+2 L^{2}+M-L M+(1+L)(1+M) N}
$$

To differentiate it with respect to L, we have:

$$
\frac{\partial P_{y}^{*}}{\partial L}=\frac{\left[1+M^{2}(N-1)+N+2 L^{2} N+4 L(1+M+N)\right]\left(a-c_{I}-c_{F}\right)}{\left(1+L+2 L^{2}+M-L M+(1+L)(1+M) N\right)^{2}}<0
$$

Proposition 5:A vertical merger causes the final goods price to decrease and social welfare to increase.

When the number of VI firms increases, there are two effects on $P_{y}$. First, there are more competitive firms, whose marginal cost of final goods is as low as $\mathrm{c}_{I}+c_{F}$, in the downstream market. Second, from proposition 4, the marginal cost of independent downstream firms also decreases with $L$. These two forces will cause the final goods market to become more competitive and social welfare to increase with $L .{ }^{9}$ This result stands in contrast to Salinger (1988), where no strategic behavior of VI firms is considered and social welfare may decline with vertical mergers, when $M$ is much larger than $L$.

\section{Conclusion}

Different from Salinger (1988) and Schrader and Martin (1998), this paper considers VI firms as Cournot players in the intermediate goods market. We emphasize that the strategic behavior of VI firms in this market affects the price of intermediate goods. In our analysis, the number of VI firms plays a crucial role. When there are a small number of VI firms, they are inclined to strategically buy or even to store up intermediate goods; and when there are a large number of VI firms, they are inclined to sell intermediate goods instead. Consequently, a vertical merger will not result in market foreclosure and it improves social welfare, because when there are more VI firms in the market, they are more likely to sell intermediate goods and the final goods price will fall as a result of falling intermediate goods price.

\section{Received 3 March 2004, Accepted 4 May 2004}

\footnotetext{
${ }^{9}$ Proposition 5 is a complement to Spengler(1950), who showed that when both the downstream and upstream are monopolized, vertical integration will avoid "double marginalization" and lower the final goods price.
} 


\section{Reference}

Greenhut, M. L. Ohta, H. (1979) "Vertical Integration of Successive Oligopolists," American Economic Review, 69(1), 137-141.

Lopatka, J. E. Godek, P. E. (1992) “Another Look at ALCOA: Raising Rivals' Cost Does Not Improve the View," Journal of Law and Economics, 35, 311-329.

Salinger, M. A. (1988) "Vertical Mergers and Market Foreclosure," Quarterly Journal of Economics, 103, 345-356.

Salop, S. C. Krattenmaker, T. G. (1986) "Anticompetitive Exclusion: Raising Rivals" Costs to Achieve Power over Price," Yale Law Journal, 96(2), 209-293.

Salop, S. C. Scheman, D. T. (1983) "Recent Advances in the Theory of Industrial Structure: Raising Rivals' Cost,” American Economic Review, 73(2), 267-271.

Salop, S. C. Scheman, D. T. (1987) “Cost-Raising Strategies,” Journal of Industrial Economics, 36(1), 19-34.

Schrader, A. Martin, S. (1998) "Vertical Market Participation," Review of Industrial Organization, 13, 321-331.

Spengler, J. (1950) "Vertical Integration and Antitrust Policy," Journal of Political Economy, 58, 347-352.

Spencer, B. J. Jones, R. W. (1992) "Trade and Protection in Vertically Related Market," Journal of International Economics, 32, 31-55. 


\section{Appendix.}

\section{The Proof of Lemma 1}

(a) The sign of $z_{j}^{*}$ depends upon the numerator of (15), which is a cubic function of $\mathrm{L}$. The third derivative of this numerator is negative and its relative minimum (maximum) is at $\mathrm{L}_{z 1}<0\left(L_{z 2}>0\right)$. Moreover, the numerator of $z_{j}^{*}$ is negative (positive) at $L=0\left(L^{*}\right)$. Figure 2 summarizes the above conditions about the numerator of $z_{j}^{*}$, and from the figure the existence and uniqueness of $L^{* *}$ are established. Note that the intercept of the $y$ axis is $1+M+N-M N$ when $L=0$.

In other words, if $L^{* *}$ exists, the $1+M+N-M N<0$.

(b) This follows directly from figure 2 .

Figure 2. The location of $L^{* *}$

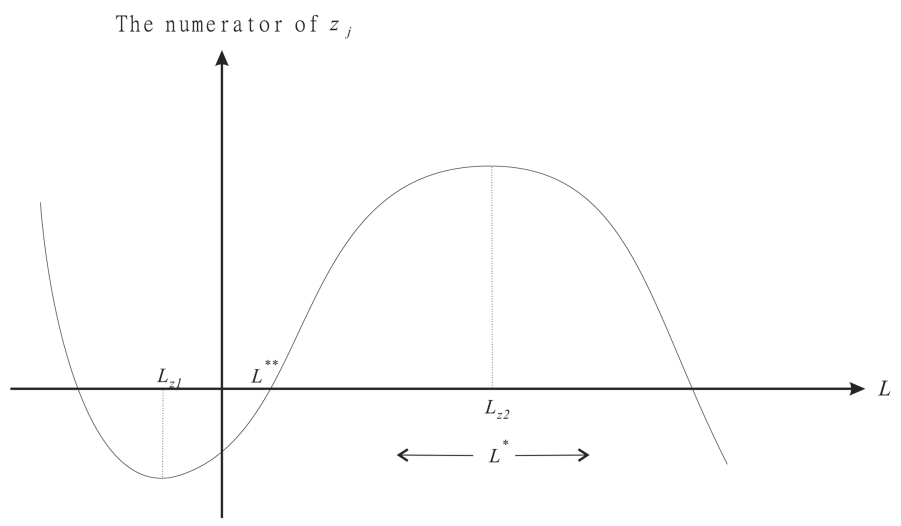

(c) From gure 2, $L^{* *} \geq 1$ if the numerator of $z_{j}^{*}$ at $L=1$ is non-positive, i.e., if $3+$ $M^{2}+2 M(3-N)+6 N \leq 0$

\section{The Proof of Lemma 2}

Let $\delta$ be the numerator of $z_{j}$ in (25) and be separated into (A) and (B) as follows:

$$
\begin{aligned}
& \delta=\underbrace{\left[1-2 L^{3}+M+N-M N+L^{2}(-3+M+2 N)+L(1+M(4+M-N)+3 N)\right]\left(a-c_{F}\right)}_{(A)} \\
& +\underbrace{(1+L)(M-L)(2+L(3+M))(N-L) c_{I}}_{(B)},
\end{aligned}
$$

where (A) is exactly the same as the numerator of $z_{j}^{*}$ in (15). It is clear that $(B)>0$ as $0<L<M(N)$. Thus, at $L=L^{* *}$, we can nd that part (A) is 0 and $\delta>0$. 
Figure 3. The location of $L^{* * *}$

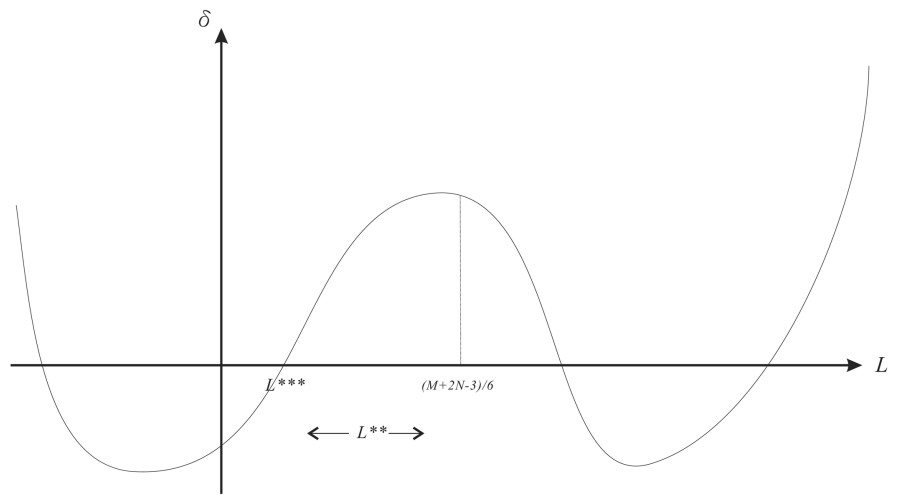

Term $\delta$ is the unit variate fourth-order function of $L$, which can be characterized as follows. First, $d^{4} \delta / d L^{4}>0$. Second, the relative maximum is to the right of $L^{* * *}$, because from the numerator of (15), we nd that $(M+2 N 3) / 6>L^{* *}$ and $d^{2} \delta / d L^{2}$ at $(M$ $+2 N-3) / 6$ is strictly negative. Third, under the necessary condition for $L^{* *}$ to exist $1+M+N-M N<0$, if $\left.\delta\right|_{L=0}>0$, then $d \delta /\left.d L\right|_{L=0}>0$.

Figure 3 summarizes the above condition of $\delta$. Therefore, if $L^{* * *}$ exists, then it must be unique.

\section{The Proof of Proposition 3}

(1). If $L<L^{* * *}$, then directly from figure 3 we nd $z_{j}^{*}<0$. This means problem (3') has an interior solution and a VI firm will keep inventory.

(2). If $L^{* * *} \leq L \leq L^{* *}$, then we know $z_{j}^{*} \geq 0$ from figure 3, which indicates a corner solution to problem ( $\left.3^{\prime}\right)$, i.e., $x_{j}+y_{j}=0$. 